\title{
Post COVID-19 and the Potential of Blended Learning in Higher Institutions: Exploring Students and Lecturers Perspectives on Learning Outcomes in Blended Learning
}

\author{
Stephen Ntim, Michael Opoku-Manu, and Anthony Addai-Amoah Kwarteng
}

\section{ABSTRACT}

This study explored students and teachers of Higher Educational Institutions perspectives on the potential of Blended Learning post-Covid19. Using Shea's 2007 Four-Model of Blended Learning and the framework of Complex Adaptive Blended Learning (BL) Systems, this paper investigated the correlation between Blended Learning (BL) and students learning outcomes in constructivists learning. The findings provided convincing support that Online Blended Learning offers some potential for teaching in higher institutions more than the stand-alone traditional face-to-face classroom. This is especially the case when teaching intends to enhance students reciprocal learning, students' inquiry-based learning, learners posing questions and seeking answers on their own, as well as promoting cooperative/collaborative learning among students. Even though, the findings did not entirely dismiss the traditional face-to-face teaching, nevertheless, the results strongly suggest that blending face-to-face teaching with online teaching offers tremendous potential for inquiry-based and constructivist learning more than the traditional classroom face-to-face teaching alone. Additionally, BL creates both cohesive and effective learning environment overcoming geographical and physical barriers of traditional classroom teaching to promote self-paced critical learning among students, especially in institutions of higher learning.

Keywords: Blended learning, constructivists, inquiry-based learning outcomes.

Published Online: November 16, 2021

ISSN: $2736-4534$

DOI :10.24018/ejedu.2021.2.6.162

S. Ntim *

Catholic University of Ghana, Ghana. (e-mail: stephen.ntim@ cug.edu.gh) M. Opoku-Manu

Catholic University of Ghana, Ghana.

(e-mail: michael.opoku@ cug.edu.gh)

A. Addai-Amoah Kwarteng

Catholic University of Ghana, Ghana.

(e-mail: addaiamoah@ cug.edu.gh)

*Corresponding Author

\section{INTRODUCTION}

One of the many alternatives to the traditional studentteacher face-to-face classroom instruction has been distance education. The underlying rationale for distance education is about ubiquity: ability for teachers to teach and students to learn regardless of geographical context (Moore \& Kearsley, 2010). Thus, geographical distance should not be a barrier to teaching and learning. (Moore and Kearsle, 2010) justifying the benefits of distance learning, clarified that the internet is not even the starting point of distance education as perceived by many authors. They categorized distance education into the following:

a) correspondence,

b) broadcast radio and television,

c) open universities,

d) teleconferencing,

e) internet/web.

It must be emphasized, that the above categories notwithstanding, it is the contemporary spread of the internet that has accelerated the popularity of distance education with consequent novelty in terminologies as 'online learning', 'elearning' or 'web-based learning' etc. The unfortunate spread of the COVID-19 pandemic globally with the consequent closure of academic institutions as one of the measures to enhance social distancing, and to control the vast spread of the pandemic, has also brought to the fore, the benefit of online learning. Online learning is generally defined as using the internet either to access learning materials, to have interactions with instructors or with the content or to interact with other learners (Anderson, 2008). Copious research has been undertaken on online learning to assess various dimensions on the subject, such as its relative impact, vis-àvis the traditional physical student-teacher face-to-face teaching. One of the contemporary topical debates has to do with whether or not, students learn better when online in relation to the traditional classroom environment. This debate has become compelling within the context of contemporary global experience. Blended learning has come to be seen as eclectic approach, in which there is an attempt to maximize the best of the two approaches- online and traditional face-toface. In an article by (Guzera and Caner, 2014), these authors 
reviewed and analyzed various published studies on blended learning through indexed articles on Google, tracing its history back to the beginnings of 2000 .

Giving a four-period space, these authors traced the history of blended learning. The first attempt to publish scholarly papers on it was from 1992-2002, in which a total of one hundred and twenty-five (125) papers were published on google. The second period which they called 'definition period', spans from 2003-2006, one thousand, two hundred $(1,200)$ articles on the subject were indexed on google. The third period is the 'popularity period', 2007-2009, one thousand, four hundred and sixty published (1460) articles on google, and the final period 'present' from 2010-2012 had estimated publication of one thousand, six hundred and sixty $(1,660)$. Given that 2012 was the cut-off date, that investigated the number of studies conducted and indexed on google, it would be interesting to find out, the perceptions and views of the clientele (consumers) of education on blended learning and students learning outcome in inquiry and constructivist learning, relative to the traditional face-to face classroom within the context of contemporary health hazards and the need for social distancing.

\section{A. Statement of the Problem}

Most research findings on students' perceptions of benefits of blended learning, relative to the traditional classroom faceto-face are not so clear cut. Findings are nuanced. Whereas some students are more satisfied with face-to-face traditional classroom teaching, especially with respect to instructional clarity, they also perceived the online learning instruction to be not so clear, even though in blended learning, they saw more improvements with respect to their skills in analyzing issues (Chen \& Jones, 2007). Thus, for some students, instructions are clearer to them when they are face to face with the teacher. This notwithstanding, some also see more improvements of this in blended learning. Similarly, in a study on the same subject, conducted by (Akkoyunlu \& Soylu, 2008), whereas students gave more score to blended learning with respect to their learning styles with 8.44 within a score range of 1-10, 1 indicated as the lowest, and 10 as the highest, students still perceived face-to-face teaching (in the classroom) as the most favored. Thus, with respect to some learning benchmarks, such as students' ability to analyze what they have learnt, using their best learning style, etc., blended learning appears to have more potential than it is with traditional classroom teaching. Another study by Chandra and (Fisher, 2009) on blended web-based learning, findings indicated respondents preferred web-based learning, more than traditional face-to-face classroom teaching for the following reasons: web-based was more convenient, more accessible, enhanced more self-autonomy in learning, heightened good interactions among friends and peers, was clear, understandable, not too difficult to follow. Above all, in web-based learning, students could ask questions from teachers just as in traditional classroom. Similarly, (So \& Brush, 2008) findings also suggested the importance of both psychological distance and social interaction in online collaborative learning. All these findings suggest that even though, most students' preferred face-to face (classroom) instructions as critical part of instruction, they still also preferred blended learning. So, there appears to be a consensus on students' perceptions: they prefer the traditional face to face, just as they do not completely write off the blended learning either, since it facilitated certain skills, such as, analytic skills and enhanced different learning styles. This is what we know from the literature for the last decade or more.

What we do not know, and need to know, is first, students' and teachers' perceptions, given the contemporary compelling challenge of the global COVID-19 pandemic, and its aftermath regarding the need for social distancing in teaching and learning. Second, we need to know, given the seriousness of the pandemic and its second and third waves in many geopolitical areas threatening another possibility of school closures, whether or not students see online learning as effective. Third, in many institutions of higher learning, most students combine work with full time studies on weekends. Many nursing mothers do the same. Given this new breed of students in Higher Institutions of Learning, it would be interesting to know, whether or not, blended learning holds the potential for designing instructional format in higher institutions. Fourth, most studies on the subject have been undertaken in geopolitical areas with developed economies, high internet accessibility and connectivity. It would be interesting to investigate the topic from less robust economy with less internet access and connectivity. Fifth, even though, most findings suggest that both traditional classroom teaching with online blended learning seem more favorable, given that most of these studies were conducted over some decades or two, and in normal times (without any global pandemic), it would be interesting to have an up-todate on students' perceptions in a more anomalous time. It is to respond to these gaps in the literature that this study was conducted.

\section{B. Research Questions}

1) How should blended learning be organized in order to support the learning of students effectively?

2) How could the constructivists and collaborative models of teaching be integrated into blended learning?

3) How could blended learning be utilized to enhance more creative and curious students to become problem solvers?

\section{Significance of the Study}

This study is significant in view of the global health crisis of the COVID-19 pandemic, and its aftermath as means to enhance social distancing. The closure of schools over a long period across many jurisdictions globally, has also raised the question of the future of education and whether or not schools in the future, and the mode of teaching will be the same again, when schools are forced to close down. To keep students academically engaged, institutions of higher learning have pushed both educators and students towards a more extensive use of modern technology, resulting to what has been termed 'blended learning'- a mixture of in-person lessons and distance learning. The over-all purpose of this hybrid approach to teaching and learning is to minimize physical attendance, in favor of video conferencing to allow for appropriate social distancing; but it is simultaneously also blended, in such a way as to go back to frontal lessons as the prevalent mode of teaching using technology to support the learning process. The whole enterprise is as new to many 
academic institutions, as it is for many heads of institutions, educational administrators, teachers, professors, students, and many other stakeholders, because it was unexpected. Given this background, the findings of this study would be significant resource to all stakeholders, especially teachers, students, and heads of academic institutions. Secondly, the outcome of this paper would help all education stakeholders, not only to come to terms with students' view of blended learning, but also, whether or not it actually supports effective learning outcomes. Third, the findings will help clarify for education stakeholders, especially academic heads and teachers, whether or not, blended learning constitute the ideal compromise for a post-pandemic society.

\section{THEORETICAL FrAMEWORK/ LitERATURE REVIEW}

A theoretical/conceptual framework of blended learning offers some direction to find answers to the question of academic access, bearing also in mind questions, such as what problems does blended learning attempt to solve? what are the underlying reason to move part of instruction out of classroom for online learning? what are the possible benefits as well as loses, etc.? Within all these, the other fundamental question for a theoretical framework on blended learning to answer is the question: what happens to learners' cognition, students' motivation as well as their affective dimension when they are engaged in online learning rather than the traditional classroom learning? (Shea, 2007). Higher Institutions of Learning, while making access to academic engagements possible for all students without restricting them to physical presence in the classrooms make two significant changes:

a) institutions reduce students' physical presence at specific place and at a particular time. In doing so, institutions of learning help students to get time to follow other pursuits such as work (for working students), child rearing (for nursing mother students) which are equally also more time and place bound,

b) the second advantage is the additional students' intake without much constraints to increase physical infrastructure. Through such mechanism, educational access is significantly increased with less additional investment in physical infrastructure (Shea, 2007).

\section{A. Shea's 2007 Four-Model of Blended Learning}

(Shea, 2007) promotes a model of blended learning which offers some kind of pyramid framework beginning with the fundamental assumptions regarding the nature of knowledge. This is followed by identifying the theories of learning that reflect these philosophical underpinnings (You, 1993). He then articulates the pedagogical approaches complementing these philosophical frameworks with the instructional strategies and the particular learning activities involved in each framework. (Shea, 2007) shows that to understand learning in a blended environment, it is important to understand several interrelated questions: how learning occurs generally among adult learners, and how it occurs in technology-specific environments. These questions help us to know that in many several ways, learning is essentially a social activity, just as it is also cognitive, and is shaped by affectivity/attitudes. Given these, social, cognitive and affectivity backgrounds, students are more likely to learn better when the environment supports these principles which he refers to as 'preconditions'. Therefore, to understand blended learning, it will be critical to consider what we know already in each of these domains, that is what we already know about learning generally, in addition to technologymediated teaching and learning.

Based on this, (Shea, 2007) comes up with four lenses through which we can view blended leanring. The first is what he calls the "How People Learn" (HPL) framework, most of which is based on Bransford, Brown, and Cocking, (2000). (Bransford, Brown \& Cocking, 2000) concluded after reviewing elements accounting for successful learning, the following four elements:

a) good learning environments are learner-centered,

b) knowledge-centered,

c) assessment-centered,

d) community centered.

The HPL framework has spurred the work of other models investigating psychological, social, and developmental influences on e-learning specifically, (e.g., McCombs \& Vakili, 2005; Shea, Fredericksen, Pickett \& Pelz, 2003). The second lenses he calls 'Principles of Good Practice in Undergraduate Education' (Chickering, \& Gamson, 1987). This strand offers a resume in research in undergraduate experience and comes up with seven (7) principles that foster good, higher-education learning environments. These include:

a) frequent contact between students and lecturers,

b) reciprocity and cooperation among students,

c) active learning,

d) prompt feedback,

e) time on task,

f) the communication of high expectations,

g) respect for diversity especially in the areas of talents and ways of learning.

One other resource used by (Shea, 2007) as framework for blended learning for adult students is (Knowles, 1980; Knowles, Holton \& Swanson, 1998) work on andragogy as well as (Fellenz and Conti, 1989) and (Merriam \& Caffarella, 1999), all of which emphasize the usefulness of learning goals, immediacy of learning application, independence, autonomy, self-direction, and ownership of learning. All these lead to satisfactory learning adult experiences. Additionally, collaboration and the sharing of life experiences in effective communities of practice (Wenger, 1991; Wenger, 2000) all facilitate adult learning and each tally with suggestions from other frameworks, such as the goals of learner-centeredness and knowledge-centeredness in the HPL framework, as well as elements of the principles of good practice in undergraduate education. The third lens is what (Shea, 2007) refers to as 'Community of Inquiry Model for Online Teaching and Learning' based on (Garrison, Anderson \& Archer, 2000). This model focuses on variety of forms of presence through which we could achieve quality learning without face-to-face teaching. There are three forms of presence:

a) teaching presence,

b) social presence,

c) cognitive presence.

The fourth lens is the community-centred approach by 
(Garrison, Anderson \& Archer, 2000). The focusing question under this model is how to develop connectedness and a sense of collaboration through online and offline learning activities. Collaboration and connectedness are the core characteristics of learning that promotes cooperation learning rather than competition for grades. Going by Vygotsky's approach, this is the type of learning that awakens different internal development processes in learners, creating a zone of 'proximal development' through interaction with people by the learner. Whereas each of the previously mentioned lenses share some commonality on the role of the community, collaboration, and cooperation as the medium for arriving at desired learning outcomes, here it might be useful to focus on the conditions that each of these conceptual framework place on a theory of learning for blended learning.

\section{B. Blended Learning (BL) and the HPL Conditions}

The first of the conditions of HPL conditions has to do with 'learner centeredness'. These are the preconditions and activities in the BL environment focusing on goals, objectives and needs as well as interests of learners. Instructional designers need to factor into to the instruction what students know through strategic guidance by the instructor because of varied student learning styles. There is the need for instructors to know who leaners are, their abilities, passions, etc., such that BL activities are also designed to align with these to put learners at the center of teaching and learning. Regarding learner motivation and engagement, it is important for $\mathrm{BL}$ environment to find out how meaningful and worthwhile content be created to enhance learner motivation and engagement. This is done when instructors using blended environments understand and leverage learners' different strengths and approaches, to assist them to be strategic about their learning. Similarly, for BL environment to arrive at the "knowledge- centeredness," BL needs to be designed to leverage the affordances of both online and traditional faceto-face settings to enhance both understanding and later transfer to new contexts (Bransford, Brown \& Cocking, 2000). This could not be accomplished unless instructors know what knowledge learners bring on board to the learning environments. Additionally, knowledge-centered learning environments also seek to enhance understanding rather than memorization, in order to foster depth of learning (Bransford et al., 2000). What are the characteristics of online learning, which, when combined with face-to-face instruction, can promote learning with understanding-meaningful learning? This has to do with assessment. The question that must be asked is: Are certain types of assessment more appropriate or more easily accomplished online - why? how? The fourth precondition for effective BL in the HPL framework is "community centered." Questions needed to be addressed by the BL instructional designer are how to promote the development of a sense of connectedness, collaboration, and a sense of safety through the integration of online and offline learning activities. Learning characterized by these are deemed to be more effective in promoting learning (Bransford et al., 2000; Johnson, Johnson \& Smith, 1991).

\section{Re-conceptualization of Blended Learning: Theory of Complex Adaptive Systems}

Learning has become more complex than it used to be due to the blending of technology-mediated learning with the traditional campus-based system of learning. This blending has not only necessitated the emergence of new elements into teaching and learning, but more especially the novelty brought about as a result of the interconnectedness between these elements. (Lim, 2002) points out that technology can precipitate novelties in the learning environment such as the activities, curriculum and the interpersonal relationships involved in teaching and learning. Based on this perception of complexity, (Lim, 2002) envisages a complex system approach to effectively address the changes and the complexity involved. The subsequent section examines some of the fundamental ideas of this complex system.

\section{Concept of the Edge of Chaosis}

The fundamental idea of the concept of 'the edge of chaosis' is that all complex systems have some predisposition or ability to bring a balance between order and chaos. This balance point is what is called the edge of chaosis. At this point, components within a system do not lock balance and at the same time they do not dissolve into turbulence either. Consequently, it is at this point where there is enough stability for self-sustenance and enough creativity to become alive. It is here that new ideas and concepts, and innovative genotypes continue to straighten up the edges of the statusquo. It is here that even entrenched archaic ideas become discarded. This concept of complex adaptive systems has been extensively utilized to have some understanding into the complexity of both dynamic as well as non-linear systems such as neural systems, galaxies, ecologies, and social systems theory (Bertalanffy, 1968; Waddington, 1977; Waldrop, 1992). It originated from the physical sciences, especially physics, chemistry, and mathematics. In the view of (Wang, Han \& Yang, 2015), the hermeneutic key to a better understanding of complex adaptive system lies with the concept of the edge of chaos as explained above. There are five (5) core attributes:

a) complexity,

b) self-organization,

c) adaptability,

d) dynamism,

e) ability to co-evolve.

Complexity: this first attribute refers to the nature of a system. Characteristically, a system is made up of a multiplicity of subsystems interconnecting with one another non-linearly. Each subsystem has its own sub-systems (Cleveland, 1994). The arrangement in complex systems is in layers of interconnectedness in such a way that each of system is part of the larger whole system. Each of the system is both autonomous as well as integrated with the various systems at its level, above it and below it.

Self-organization: this second attribute underscores two shades of meanings:

(1) the subsystems within a system interact with one another through feedback and iteration and it is interaction which gives birth to new orders or patterns of relationship between their inner elements,

(2) this instantaneous emergence of new order is not imposed by any external forces (Cleveland, 1994).

Adaptability: this illustrates a process, and this process for most of the time is triggered by the systems' ability to "form new rules from combinations of old rules and new information from the environment (Cleveland, 1994). This 
has to do with the systems' natural selection process of evolution in which the fittest survive.

Dynamism portrays the ability of complex adaptive systems to be poised on the edge of chaos-stable enough to maintain their structure, but sensitive enough to external changes that they can undergo rapid and unpredictable periods of change (Cleveland, 1994). Being dynamic is seen to be the ideal state that a living system should maintain, stable but not static, transformative but not chaotic.

The ability to co-evolve refers to subsystems acting upon each other to form a fitness landscape that is constantly changing as they change (Cleveland, 1994). A key idea which underscores the concept of co-evolution is the mutual and multiple impacts between a subsystem and the systems around it, resulting in adaption to one another (also see Kauffman, 1993; Kauffman, 1995). In summary, complex adaptive systems are dynamic and open. They have an inbuilt innate capability to self-organize, adapt to, and evolve with their environment. Such a system view provides a different lens through which to examine the nature of blended learning.

\section{E. Complex Adaptive Systems Framework: Implications for Blended Learning}

(Branch, 1999; You, 1993) have conceptualized learning as a complex and dynamic system. For example, (Branch, 1999) identified eight subsystems in the system of learning as follows: students, content, media, teachers, peers, time, goal, and context. Based on this conceptualization, (Wang, et al., 2015). borrowing ideas from Branch (1999) and You, (1993). proposed the subsequent six-dimensional framework which they referred to as the Complex Adaptive Blended Learning System (CABLS).

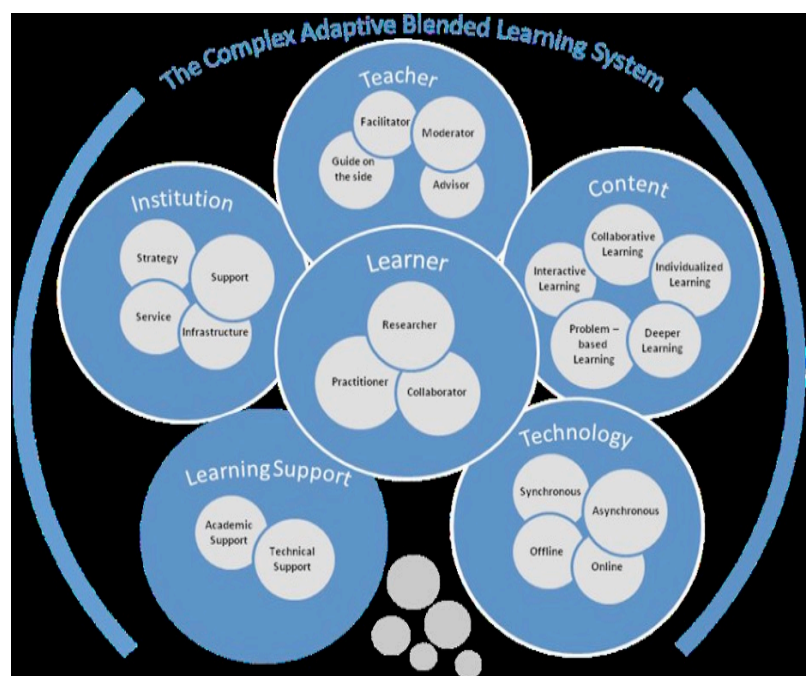

Fig. 1. The Framework of Complex Adaptive Blended Learning Systems (CABLS) (culled from Wang, Han, \& Yang 2015).

The Fig. 1 above illustrates how the framework of Complex Adaptive Blended systems (CABL) interact in the six subsystems of the learner, the teacher, the technology, the content, the learning support, and the institution and how they relate to each other. Comparable to the Complex Adaptive System in the physical sciences, these six instructional systems do not only act within themselves and upon each other dynamically and non-linearly, but each of these six elements has its typical characteristics and internal forces.
These internal forces are consequent upon the other surrounding subsystems for maintaining its vitality. All interact with one another to form this system of blended learning. The following are brief explanations of how the six elements interact in the framework.

\section{1) Learner Behavior in CABLS}

Given that Complex Adaptive Blended Learning Systems (CABLS) is hypothesized to consist of a complex subsystem, what this implies is that the learner continually interacts and evolves with the other system. Hence, the learner is constantly acquiring new identities transforming the learner from passivity into active learner. The fundamental reason for this transformation is the continuous dynamic process of change as learners within the multimodal learning space become more adaptive through the interaction with the other systems.

\section{2) Teacher Behaviour in CABLS}

Similarly, just as students continue to interact with other subsystems and evolve, so also teachers in blended learning also continually interact not only with other subsystem but more particularly with learners to acquire new identities to become multi-disciplined professional skills, making them become facilitators, e-moderators' advisors, guides etc.

\section{3) Content in $C A B L S$}

Content for teaching and learning has never been richer than in blended learning. The richness lies in the fact that it becomes more engaging because of the constant interaction with many other systems- the learner, the teacher, technology, the learning support as well as the institutions. This is what (Singh, 2010). refers to as categorization of blended learning which include the following: blending offline and online learning; blending self-paced and live, collaborative learning; blending structured and unstructured learning; blending custom content with off-the-shelf content; and blending learning, practice, and performance support. (Moor and Gilmartin, 2010) empirical study have been cited as one of the empirical findings supporting deeper learning caused by new content in blended learning.

\section{4) Technology in CABLS}

The complexity of technology has been recognized by scholars who identify the multiplicity of interactions between and within technology and the environment which have not been adequately addressed in research (Ni \& Branch, 2008). Technology continues to be advanced and in so doing it has a tendency to rejuvenate blended learning and at the same time keeping blended learning balanced in maintaining internal structure and simultaneously being sensitive to consistent changing needs of students as well as potential challenges in respect of emerging technologies.

\section{5) Learning Support in CABLS}

One significant point of the CABLS framework distinguishing it from other models of blended learning is its emphasis on learning support. This is because for CABLS, the learner has control over his/her learning and focuses much on learner-centered approach. There are two kinds of learning support: academic support and technical support. The first has to do with assisting learners to develop effective learning strategies (e.g., time management and collaborative skills) and the second helps students improve their knowledge, skills 
and use of tools of technology. Additionally, the development of learning support is influenced by needs of learners as well as the expertise of the teacher in the context of constant advances in technology needs enhanced through institutional support.

\section{6) The Institution in CABLS}

The CABLS framework sees blended learning within the context of the institution where learning is taking place. Thus, sustainability of blended learning is intrinsically related to the support mechanisms such as:

a) strategies,

b) policies,

c)support and services offered by the institution (Graham, Woodfield \& Harrison, 2013).

These institutional mechanisms are interrelated and informed by the other variables within the CABLS such as the learner, the teacher, the technology, the content, and the learning support. In turn, the institution becomes a major driving force behind the development of the subsystems around it. In summary, there are two interrelated variables in the CABLS framework of blended learning: a) interdependence and b) the dynamism of the interactions between the systems underscores the difference between CABLS and other models of blended learning.

\section{F. Theoretical Model of Complex Constructivism: Implications for Complex Adaptive Blended Learning Systems}

Education generally has been underscored over the years by its specific metaphors. These metaphors have not only implicated teaching and learning but have also influenced educational research and educational practice (Leary, 1990). From the 1800's to date, three metaphors have dominated education, and consequently influenced teaching and learning. They are:

a) learning as the acquisition of stimulus-response pairs (behaviorism),

b) learning as the processing of information (information processing),

c) learning as the construction of knowledge (constructivism).

Since 2008, there has been a new metaphor: learning as self-organized adaptation based in complexity theory (Brown, 2008). The commonality between contemporary complex theory of constructivism and behaviorisms, information processing and the other variants of constructivism (trial, social, radical) is that in all these, components parts are important. Nevertheless, in complex theory of constructivism, what is critical of an agent (a neuron, a neural group, an experience, an individual or group of individuals) are not the agents themselves, but rather how these agents interact with each other (Holland, 1995). Constructivism and complex constructivism both recognize the challenge to predict global behavior from an understanding of the parts (Guanglu, 2013; Waldrop, 1992). Rather, what is typical with this complexity-based alternative is to understand the global by understanding the interaction of its parts (Cilliers, 2010; Lewin 1992). This is conceptually related to the Complex Adaptive Blended Learning Systems explained in the earlier section. That is, what characterizes the complex constructivism is one in which the type of learning embraced is the non-liner, adaptive and constructive one. Just as the learner is at the centre of the Complex Adaptive Blended Learning system surrounded by and interacting with other 'agents', so also, the Complex Constructivism metaphor. This model perceives learning as the active construction and adaptation of learners' internal models of reality. This is based on the interaction between the learner and all other agents his/her environment. This includes other persons-teachers, content, institutional support, IT etc., such that the functioning of one's internal models exceeds the sum of the models' components (Doolittle \& Hicks, 2003).

\section{G. Summary and Present Study}

Higher institutions today, especially with the COVID-19 pandemic and its aftermath, while making access to academic engagements possible without restricting students to physical presence have precipitated two significant changes in instructional delivery: reducing physical presence at specific place and transition from traditional classroom to online/distance learning. Two theoretical/conceptual frameworks have been underscored in this paper as institutions make academic access possible to all, with little restriction to physical presence: Shea's four model of blended learning theory and the CABLS framework of blended learning. Even though, the two theoretical models of blended learning differ in many respects, there are still some points of intersection: the emphasis on the constructivist approach to learning, i.e., the student-centered learning, and focus on the learner as an active agent of learning through the use of modern technology. Given that the two-framework examined above, put the learner at the center of teaching and learning, with focus on motivation and other affective dimensions of learners, (as established in the literature reviewed above), it would be important to investigate from other geopolitical areas whether or not blended learning enhances effective learning outcome. This is especially so, when the above theoretical literature clearly underscores the concepts of reciprocity, cooperation, and active learning, as well as continuous interaction and evolution with other systems. It would be important to test, whether or not these theorical concepts in the literature could be validated among learners, most of who are combining full time work with full-time learning on weekends from a less robust economy. It would be interesting to find out how these new hybrids of students acquire new identity, and whether this new identity also transforms them from being passive learners to becoming active curious learners. It is to test these theories empirically, that this current study investigated the following:

a) how blended learning enhances students' creative curiosity,

b) how constructivists and collaborative models of teaching could be integrated into blended learning,

c) how blended learning could be utilized to enhance more creative and curious students to become problem solvers.

Again, most of the literature/theories reviewed originated some ten years ago during normal period. It would be interesting to find out whether or not, these theories hold, especially within this period of global pandemic. This pandemic has reinforced the need for social distancing. In order to keep students academically engaged, online teaching 
learning has become necessary.

We need to examine whether or not learning outcome is effective in engaging students to become more constructive, more creative, and more adaptive in blended learning as the theories examined above seem to suggest.

\section{Methodology}

\section{A. Sample}

This research being reported involved an empirical study conducted during the COVID-19 school closure from March 2019 through to June 2021, when the universities resumed in Ghana on January 2021. This report covers roughly three (3) consecutive semesters from Semester 2/2019 through to Semester 1/2020 and Semester 2/2021. A stratified purposive sampling of two hundred and sixty (260) postgraduates' students and forty (40) lecturers, totaling three hundred (300) took part in this survey conducted in four (4) universities in the middle belt of Ghana- the Ashanti and Bono regions, namely, the Kumasi Metropolis (2 universities) and the Sunyani Municipality (2 universities). Students were within the age range 25- 35 years. In terms of gender, a quarter (65 out of the 260) were females and the rest were males. Thirty (30) of the forty (40) lecturers were males, and the remaining ten (10) were females, having taught in the universities ranging from five (5) years to fifteen (15) years. All the students were postgraduates, pursuing different academic programmes ranging from Business to Education and other social sciences, Language, Engineering, and Medicine. Apart from the Professional students in Medicine and Engineering who were full time students, about one hundred and ninetyfive (195) of the remaining students were combining parttime weekend studies with full time work, especially the Education and the MBA students. Sixty percent of the students had completed their course work and were in their first semester of the thesis year.

\section{B. Measures}

a) The survey instrument was limited to three pages in order to encourage greater student participation without too much time and required approximately 10 to 15 minutes to complete. The survey had three sections. The first section asked for information regarding the socioeconomic and educational background of respondents. The second part examined respondents study preferences especially the traditional face-to-face teaching vis-à-vis the various blended learning options that were available to them. Respondents were examined on the following five (5) measures adapted from (Jones, 2006). Under the following:

a) face-to face (No ICT support),

b) basic ICT use (Use ICT for simple presentation),

c) E-enhanced (Use ICT for announcement, lecture notes, basic communication),

d) E-focused (online assessment, online discussions, interactive materials and E-intensive (complete modules delivered and moderated online).

Each of the options were listed and students were asked to rate their effectiveness of each in assisting their learning by using a 4-point rating scale.

The third section provided an overview for respondents' perspectives on constructivists and collaborative models of teaching, and how they are effective in blended learning. Some of the variables of constructivists model of teaching investigated included:

a) reciprocal teaching/learning: allowing pairs of students to teach each other using IT,

b) Inquiry-based learning (IBL), learners posing their own questions and seeking answers to their questions via research and direct observation outside of the traditional face-to face,

c) Cooperative learning. The fourth section focused on how blended learning could be utilized to enhance students' creativity and curiosity to become problem solvers.

Four measures were measured: using blended learning through virtual (IT) to demonstrate/teach students:

a) how to define a problem,

b) help students to generate alternative solutions,

c) demonstrate to students how to evaluate and select alternative solution,

d) how to implement a follow-up solution. All scores were coded into means and standard deviations.

The findings of this study are presented in this section in accordance with the research questions.

\section{FINDINGS}

A. Research Question 1: Students Study Preferences in $B L$ and Their Relative Effectiveness in Achieving Learning Outcomes

TABLE I: MEAN SCORES OF BL PREFERENCES AND THEIR RELATIVENESS

\begin{tabular}{ccccc}
\multicolumn{5}{c}{ IN LEARNING OUTCOMES } \\
\hline \hline Measure & Mean & SD & Mean & SD \\
\hline No ICT & 10 & 0.05 & 0.15 & 0.15 \\
Basic ICT & 0.35 & 0.34 & 0.30 & 0.30 \\
E-Enhanced & 0.38 & 0.35 & 0.30 & 0.31 \\
E-focused & 0.98 & 0.34 & 0.90 & 0.30 \\
E- Intensive & 0.58 & 0.34 & 0.90 & 0.25 \\
\hline \hline
\end{tabular}

TABLE II: SUMMARY OF LINEAR REGRESSION ANALYSIS

\begin{tabular}{cccc}
\hline \hline $\mathrm{R}$ & R Square & $\begin{array}{c}\text { Adjusted R } \\
\text { Square }\end{array}$ & Std Error \\
\hline 0.487 & 0.242 & 0.236 & 7.704 \\
\hline \hline
\end{tabular}

Based on the raw scores in Table I, Table II presents a summary of the linear regression. The value of ' $R$ ' in Table II underscores the degree of correlation between the independent (predictor) variable namely, the different variants of Blended Learning and the dependent (criterion) variable, that is learning outcome. Table II shows positive and moderate correlation $(\mathrm{r}=0.49)$ between students mean score of blended learning and learning outcome. The model moderately predicts respondents learning outcome which is dependent on the predicting variables of the Blended Learning. The ' $R$ '-square value is the coefficient of determination. It shows how much of the variability in the dependent variable is explained by the independent variable. Table II shows that about $24 \%$ of the variability in students' learning outcomes could be explained by the independent variable, that is Blended Learning. The coefficient values of the independent variables as well as the constant term of the estimate of the linear regression model is found in Table III.

TABLE III: COEFFICIENT OF LINEAR REGRESSION 


\begin{tabular}{ccccccc}
\hline \hline Model & \multicolumn{2}{c}{$\begin{array}{c}\text { Unstandardized } \\
\text { Coefficients }\end{array}$} & $\begin{array}{c}\text { Standardized } \\
\text { Coefficients }\end{array}$ & \multirow{2}{*}{ T } & Sig. \\
& $\mathrm{B}$ & Std. Error & Beta & & \\
\hline Constant & 11.819 & 3.056 & & 3.870 & 0.000 \\
Blended Learning & 0.312 & 0.035 & 0.490 & 9.034 & 0.000 \\
\hline \hline
\end{tabular}

\begin{tabular}{ccccc}
\hline \hline Problem solvers & $\begin{array}{c}\text { Levene's } \\
\text { statistic }\end{array}$ & dfl & $\begin{array}{c}\text { df2 } \\
\text { Group }\end{array}$ & Sig \\
\hline & 0.232 & 2 & 297 & 0.79 \\
\hline
\end{tabular}

Table III provides the required coefficients indicated under ' $\mathrm{B}$ ' below the 'Unstandardized Coefficients'. The constant value 11.82 is indicative of respondents estimated learning outcome relative to no identified variant of $\mathrm{BL}$ and therefore is equal to 0 . The coefficient 0.31 is the slope of the predictor variable which tells the average increase in learning outcome when there is a unit increase in Blended Learning. After obtaining the equation between the two variables, we determined how significant the effect of the predictor variable $\mathrm{BL}$ was, using the results from the ANOVA test of significance presented in Table IV.

TABLE IV: ANOVA TEST OF SIGNIFICANCE OF PREDICTOR VARIABLE

\begin{tabular}{cccccc}
\hline \hline & Sum of & Df & $\begin{array}{c}\text { Mean } \\
\text { Square }\end{array}$ & F & Significance \\
& Squares & & Squar \\
\hline Regression & 4720.093 & 1 & 4720.093 & 81.605 & 0.000 \\
Residual & 14922.892 & 258 & 57.841 & & \\
Total & 19642.985 & 259 & & & \\
\hline \hline
\end{tabular}

\begin{tabular}{cccccc}
\multicolumn{6}{c}{ TABLE IX: ANOVA } \\
\hline \hline Problem solvers & $\begin{array}{c}\text { Sum of } \\
\text { squares }\end{array}$ & Df & $\begin{array}{c}\text { Mean } \\
\text { Square }\end{array}$ & F & Sig \\
\hline Between groups & 1632.667 & 2 & 816.33 & 5.374 & 0.005 \\
Within Groups & 45113.000 & 297 & 151.896 & & \\
Total & 46745.667 & 299 & & & \\
\hline \hline
\end{tabular}

\section{DISCUSSION}

The need for social distancing in teaching and learning in the history of higher institutions of learning has never been dire as it has become of late due to the COVID-19 pandemic. It appears academic institutions would have to come to terms with both face-to-face teaching as well as online teaching, the hybrid of which, has come to be referred to as 'blended learning'. It is based on the criticality of this contemporary mixed approach to teaching and learning that this study explored students and teachers' study and teaching preferences using five (5) measures to examine how in their view, blended learning enhanced effective teaching and

TABLE V: COMPARISON OF MEAN SCORES ON THREE PROMINENT BL PREFERENCES

\begin{tabular}{cccc}
\multicolumn{4}{c}{ PREFERENCES } \\
\hline \hline & & Mean Difference & p-Value \\
\hline \hline E-intensive & E-focused & 6.089 & 0.000 \\
E-focused & E-enhanced & 8.899 & 0.000 \\
E-intensive & E-enhanced & 5.809 & 0.000 \\
\hline \hline
\end{tabular}

The test of significance was conducted at 5\% level of significance and the indication is that the predictor variable was significant given that $\mathrm{F}$-ratio of 81.61 with $\mathrm{p}<0.05$. This shows that blended learning has significant contribution to students learning outcomes. Since the test of significance showed the predictor variable to be significant, we needed to tease out from among the five variants of BL the first three prominent $\mathrm{BL}$ to compare the three to know where the difference was. Games-Howell test was run as indicated in Table V

B. Research Question 2: How could the Constructivists and Collaborative Models of Teaching Be Integrated into Blended Learning?

TABLE VI: DESCRIPTIVE STATISTICS ON CONSTRUCTIVISTS AND COLlabORATIVE TEACHING

\begin{tabular}{cccc}
\hline \hline Measure & N & Mean & Std. Drv. \\
\hline \hline Reciprocal Teaching/Learning & 300 & 96.00 & 0.002 \\
Inquiry-based Learning & 300 & 97.00 & 0.013 \\
Leaners posing questions/seeking & 300 & 95.00 & 0.021 \\
answers outside traditional face-to-face & 300 & 92.00 & 0.05 \\
Cooperative/Collaborative Learning & & \\
\hline \hline
\end{tabular}

TABLE VII: SCORES ON BLENDED LEARNING AND STUDENTS' CREATIVITY TO BECOME PROBLEM SOLVERS

\begin{tabular}{cccc}
\hline \hline Measure & $\mathrm{N}$ & Mean & Std. Drv. \\
\hline $\begin{array}{c}\text { Using BL to teach students } \\
\text { problem identification }\end{array}$ & 300 & 55.50 & 12.27 \\
$\begin{array}{c}\text { Using BL to help students } \\
\text { generate alternative solution }\end{array}$ & 300 & 55.80 & 11.95 \\
$\begin{array}{c}\text { Using BL to teach students how } \\
\text { to evaluate and select alternative } \\
\text { solution }\end{array}$ & 300 & 55.00 & 12.75 \\
$\begin{array}{c}\text { Using BL to teach students how } \\
\text { to implement a follow-up plan }\end{array}$ & 300 & 54.75 & 12.45 \\
\hline \hline
\end{tabular}

a) face-to face (No ICT support),

b) basic ICT use (Use ICT for simple presentation),

c) E-enhanced (Use ICT for announcement, lecture notes, basic communication),

d) E-focused (online assessment, online discussions, interactive materials and E-intensive (complete modules delivered and moderated online).

Each of the options were listed and students and teachers were asked to rate their effectiveness of each under various variables and how these assisted their learning. Notwithstanding the conflicting findings in the literature, some findings suggesting that blended teaching enhanced learning outcomes, while others maintain it does not, the one major finding of this study from the data above suggest that over-all, blended learning in its different variants enhanced effective learning outcomes but with some nuances. While descriptive statistics in Table I indicated teachers and students mean preferences to be $4.90(\mathrm{SD}=1.25)$ and 4.58 $(\mathrm{SD}=1.34)$ to be the highest, that is $\mathrm{E}$ - intensive, relative to other four, the ANOVA test of significance that was conducted in Table IV at 5\% level of significance, indicated that the predictor variable, namely blended learning, was significant given that F-ratio of 81.61 with $\mathrm{p}<0.05$.

This showed that blended learning had significant contribution to students learning outcomes by and large. However, when respondents were probed further to indicate which of the first three prominent blended learning were their preferences, E-focused and E-enhanced, respectively had the highest mean differences of 8.99 and 6.089 (Table IV), followed by E-intensive and E-focused, etc. It is significant to note from the data above, that nowhere did respondents indicate a preference for 'NO ICT' or even 'Basic ICT Use'. We interpreted this result to mean that respondents wanted to go beyond merely using basic ICT for simple presentation and wanted more intensive use of IT for teaching. Respondents did not completely rule out face-to-face learning environments since it was understood to be essential part of 
blended learning. The findings in this study therefore corroborate other empirical studies such as (Chen \& Jones, 2007) as well as (Akkoyunlu \& Soylu, 2008) on the usefulness of blended learning.

Another major finding in this study has to do with the debate whether or not students learn better online, relative to traditional classroom. The data in this current study showed that with respect to constructivists and collaborative learning, blended learning (online) appears to enhance more learning outcomes than the traditional face-to- face classroom learning, especially in such areas as inquiry-based learning, reciprocal teaching and learning, learners posing questions or seeking answers from teachers and cooperative/collaborative learning, etc. Students appeared to feel less intimidated because of social/psychological distance than the physical presence of a teacher in the traditional classroom.

This finding in the second research question showed a strong positive relationship between blended online learning and constructivist/inquiry learning supporting the empirical study of (Hong, 2003). Online teaching effectively promotes the constructivists approach to learning. The instructor provides the needed supporting skills and knowledge to each learner, which when compared to the traditional face-to-face classroom, has some features such as overcoming geographic limitations. The learner could enter the virtual classroom and learn on his/her own anytime and anywhere and interact with peers so far as there is access to the Internet. This finding is conceptually not too different from the Complex Adaptive Blended Learning Systems. The type of learning embraced in the data appears to be the non-liner, adaptive and constructive one, surrounded by and interacting with other 'agents'. Learning as perceived by respondents with emphasis on different shades of constructivism appears to be that students and teachers seemed to perceive online learning more than face-to-face, as the active construction and adaptation of learners' internal models of reality, based on the interaction between the learner and all other agents (Doolittle \& Hicks, 2003). This was found to be more enhanced, when online was complemented by classroom-face-to face. Again, blended learning as suggested in this study, seems to hold the key to future teaching and learning. In terms of meta-analysis empirical studies, the finding reported here support the metaanalysis studies conducted by (Means, Yukie, Murphy and Baki, 2013). that showed that on average, students who studied in online learning conditions by and large, modestly outperformed learners who received instructions through the medium of the traditional face-to-classroom teaching alone. The advantage in terms of significance was in favor of only those studies that contrasted blended learning with the traditional face-to-face instruction, but less of those that contrasted only face-to-face with online conditions. What this implies is that blended learning, even though it involves additional learning time, more instructional resources as well as course elements, but all these additional resources most likely appear to have encouraged more interactions among learners in this study than only face-to-face classroom or purely online teaching. Another meta-analysis of distance education by (Zhao et al., 2005) and (Bernard et al., 2004), examined 98 effect sizes from 51 studies that were published from1996 to 2002.

This meta-analysis investigated distance course that were mediated through multiplicity of technology from different learners. The over-all effect size was found near zero $(\mathrm{d}=$ +0.10 ). Later moderator analyses found that those studies that used blended approaches in which $60-70 \%$ of learning was done through technology, found significant positive effects compared to face-to-face instruction than that of pure distance learning studies did. Thus, the difference between blended learning and face-to-face classroom instruction was much larger than was found between distance education, that was almost entirely mediated by technology and classroom instruction, supporting the findings of this present study.

Online learning and constructivists reform movements in science education has underscored how science education in contemporary pedagogy is heavily influenced by constructivists learning theories (National Research Council, 2006). Again, the findings in this study strengthen this claim. These learning theories based on the general cognitivists theory of learning see the learner as the sole constructor of knowledge and therefore emphasizes the importance of the learner's inquiry processes. Even though, the constructivist inquiry-based science education, laboratory experiences are critical part of instruction providing student with the opportunities to observe and make sense of the world around them. However, this raises the question of how this is possible in online learning. This notwithstanding, even here, there is evidence of stimulated as well as virtual laboratories, not only playing important role to stimulate students constructing their own knowledge, but more importantly, stimulated, and virtual labs, were seen to be even better suited in some instructional goals than the hands-on laboratory face-to-face learning.

Additionally, constructivist teaching requires students to make their process visible, and teacher to be responsive to student thinking, both of which are typically seen to be more challenging in online environments (Crippen et al., 2013). However, with intentional design, these features can be incorporated into online science courses. The findings in this study even though not specifically on science education, appear to confirm such predictions that online teaching more than face-to-face enhances students critical thinking and reflection (Jang, 2009; Means et al., 2013). The over-all findings of this paper support the new metaphor of learning which perceives learning as more of a self-organized adaption, which constitutes the essence of the complexity theory of (Brown, 2008). as well as the complex theory of constructivism. In constructivism theory, what is deemed critical of an agent, whether a neuron, a neural group, an individual or a group etc., are not so much these agents themselves, as how these agents interact among themselves, and with each other. The higher scores on the descriptive statistics in Table I on E-intensive as well as on Table $\mathrm{V}$ on constructivist and collaborative learning confirm the fundamental concepts of the theoretical model of complex constructivism, and its practical implications for blended learning systems. Based on this, the current study supported by other empirical studies seems to suggest that a hybrid of face-to-face classroom learning, and online learning (blended learning) seems to hold the key for teaching and learning in higher institutions in the future. 


\section{CONCLUSION}

This study gauged students and teachers of Higher Educational Institutions perspectives on the potential of Blended Learning post-COVID-19, using (Shea, 2007) Model of Blended Learning and the framework of Complex Adaptive Blended Learning Systems to examine the correlation between Blended Learning and the constructivists learning and students learning outcomes. The results of the research questions that guided this paper provided convincing support that online Blended Learning offers some potential for teaching in higher institutions more than the stand-alone traditional face-to-face classroom, especially when it comes to enhancing students reciprocal teaching and learning, students' inquiry-based learning, learners posing questions and seeking answers on their own, as well as promoting cooperative/collaborative learning among students.

Even though the findings did not dismiss traditional faceto-face teaching, making it a hybrid of online teaching that is blended learning, offers tremendous potential value to education stakeholders such as students, educational managers, curriculum designers as well as the entire faculty members since Blended Learning creates both cohesive and effective learning environment overcoming geographical and physical barriers of traditional face-to- classroom teaching.

Additionally, this research was carried out in a study area with fragile economy and less access to internet connectivity with postgraduate students in selected universities, many of whom were combining full time study with work on weekends. It would be interesting for further research to be conducted in this same study area with pre-tertiary students, especially students in the senior high schools to examine whether with high internet inaccessibility at that level, students would still see any potential for blended learning post COVID-19, whether BL, vis-à-vis the stand-alone traditional face-to face classroom teaching, mediates more effectively the constructivist learning outcome to make students more active learners.

\section{ACKNOWLEDGMENT}

The study reported here benefits from input received from students and lecturers' respondents from selected universities in Ghana in response to our request for needed information for this paper. We would like to acknowledge all respondents who voluntarily participated in the study as well as all authors whose references have been cited in this study. This research was undertaken without any funding from any source

\section{REFERENCES}

Akkoyunlu, B., Soylu, M. Y. (2008). A study of student's perceptions in a blended learning environment based on different learning styles Educational Technology \& Society, 11(1), 183-193. 2008.

Anderson, T. (2008). The Theory and practice of Online Learning. 2nd ed. Athabasca University Press.

Bernard, R. M., Abrami, P. C., Lou, Y., Borokhovski, E., Wade, A., Wozney, L., Wallet, P. A., Huang, B. (2004). How does distance education compare with classroom instruction? A meta-analysis of the empirical literature". Review of Educational Research, 74(3), 379-439.

Bertalanffy, L. V. (1968). General system Theory foundations, Development. New York George Braziller.
Branch, R. (1999). Instructional design: A parallel processor for navigating learning space. Design Approaches and Tools in Education and Training. Dordrecht.

Bransford, D., Brown, A., Cocking, R. (2000). How people learn: brain, mind, experience and school. committee on developments in the science of learning, commission on behavioral and social sciences and education, national research council. Washington, D.C.: National Academy Press.

Brown, C. (2008). The use of complex adaptive systems as a generative metaphor in an action research study of an organization. Qualitative Report, 13(3), 416-431 2008.

Chandra, V., Fisher, D.L (2009). Students' perceptions of a blended webbased learning environment. Learning Environment Research, 12, 3144.

Chen, C. C., Jones, K. T. (2007). Blended learning vs. traditional classroom settings: Assessing effectiveness and student perceptions in an mba accounting course The Journal of Educators Online, 4, (1). 1-15.

Chickering, A. W., Gamson, A. F. (1987) Seven principles for good practice in Undergraduate Education. Racine, WI: The Johnson Foundation, Inc. Wingspread

Cilliers, P. (2010). The value of complexity. Complicity: An International Journal of Complexity and Education. 7(1), 39-42.

Cleveland, J. (1994). Complexity theory: Basic concepts and application to systems thinking. Innovation Network for Communities. 27.

Crippen, K. J., Archambault, L. M., Kern, C. L. (2013) The nature of laboratory learning experiences in secondary science online Research in Science Education, 43(3), 1029-1050.

Doolittle, P. E., Hicks, D. (2003). Constructivism as a theoretical foundation for the use of technology in social studies. Theory and Research in Social Education. 31(1), 72-104.

Fellenz, R., Conti, G. (1989). Learning and reality: Reflections on trends in adult learning. ERIC Clearing House on Adult Career and Education and Training Information Series (No. 336), 1989.

Garrison, D. R., Archer, W. (2000). Critical inquiry in a text- based environment: Computer conferencing in higher education Internet and Higher Education. 11(2), 1-14.

Graham, C. R., Woodfield, W., Harrison, J. B. (2013). A framework for institutional adoption and implementation of blended learning in higher education". The Internet and Higher Education, 18, 4-14.

Guanglu, Z. (2013). On the recursion between teaching and learning. Complicity: An International Journal of Complexity and Education. 9(1), 90-97.

Guzera B., Caner, H. (2014). The past, present and future of blended leanring: An in-depth analysis of literature $5^{\text {th }}$ World Conference on Educational Sciences Procedia - Social and Behavioral Sciences. 116 $4596-46032$.

Holland, J. H. (1995). Hidden order: How adaptation builds complexity. New York, NY: Addison-Wesley 1995

Hong, Z. (2003). Constructivism in online learning: A literature review graduate research Papers 2. 853https://scholarworks.uni.edu/grp/853

Jaber L., Dini Z., Hammer V., Danahy, E. (2018) Targeting disciplinary practices in an online learning environment Science Education. 102 (4), 668-692.

Jang, S. J. (2009). Exploration of secondary students' creativity by integrating web-based technology into an innovative science curriculum. Computers \& Education. 52(1), 247-255.

Johnson, D. W., Johnson, R. T., Smith, K. A. (1991) Active learning: Cooperation in the College Classroom. Edina, MN: Interaction Book Co.

Jones, N. (2006). E-College Wales, A case study of blended learning. Handbook of blended learning: Global Perspectives, Local designs. Pfeiffer Publishing, San Francisco, CA.

Kauffman, S. A. (1993). The origins of order: Self-organization and Selection in evolution. Oxford, UK: Oxford University Press.

Kauffman, S. A. (1995). At home in the universe: The search for laws of selforganization and complexity. London, UK: Viking

Knowles, M. (1980). The modern practice of Adult Education: From pedagogy to andragogy 2nd ed. Englewood Cliffs, NJ: Prentice Hall, Cambridge.

Knowles, M. (1984). Andragogy in Action: Applying Modern Principles of Adult Education. San Francisco, CA: Jossey-Bass.

Knowles, M. Holton, E. \& Swanson, R. (1998). The Adult Learner. Houston, TX: Gulf.

Leary, D. E. (1990). Psyche's muse: The role of metaphor in the history of psychology. Metaphors in the history of Psychology. 1-78.

Lewin, R. (1992). Complexity: Life at the edge of chaos. New York, NY: Collier.

Lim, C. P. (2002). A theoretical framework for the study of ICT in schools: A proposal. British Journal of Educational Technology. 33(4), 415426. 
McCombs, B., Vakili, D. (2005) A learner-centered framework for elearning Teachers College Record. 107(8), 1582-1600.

Means, B., Yukie, T., Murphy R., Baki, M. (2013). The effectiveness of online and blended learning: A meta-analysis of the Empirical Literature. Teachers College Record. 115(3), 1-47.

Merriam, S., Caffarella, R. (1999). Learning in adulthood: A comprehensive guide. San Francisco, CA: Jossey-Bass.

Moor, N., Gilmartin, M. (2010) Teaching for better learning: A blended learning pilot project with first-year geography undergraduates. Journal of Geography in Higher Education. 34(3), 327-344.

Moore, M. G., Kearsley, G. (2010) Distance education: A systems view of Online Learning 3rd ed Wadsworth: Cengage Learning.

National Research Council. (2006) America's lab report: Investigations in high school science. National Academies Press.

Ni, X., Branch, R. M. (2008). Complexity theory. Handbook of research on educational communications and technology. 3rd ed. Mahwah, NJ: Lawrence Erlbaum,

Psychology. Cambridge, UK: Cambridge University Press,

Shea, P., Fredericksen, E., Pickett, A., Pelz, W. (2003). Faculty development, student satisfaction, and reported learning in The SUNY Learning Network. Learner centered theory and practice in distance education. Mahwah, NJ: Lawrence Erlbaum.

Shea, P. (2007) Towards a conceptual framework for learning in blended environments. Blended Learning: Research Perspectives, 19-35. Needham, MA: Sloan Consortium.

Singh, H. (2010). Building effective blended learning programs. Educational Technology. 43(6), 51-54.

So, H-J., Brush, T. A. (2008). Students' perceptions of collaborative learning, social presence and satisfaction in a blended learning environment: Relationships and critical factors. Computers \& Education. 51(1), 318-336.

Waddington, C. (1977) Tools for thought. New York, NY: Basic Books.

Waldrop, M. M. (1992) Complexity: The emerging science at the edge of order and chaos. New York NY: Simon \& Schuster.

Wang, Y., Han, X., Yang, J. (2015) Revisiting the blended learning literature: Using a complex adaptive systems framework. Educational Technology \& Society. 18(2), 380-393.

Wenger, E. (1991) Situated learning: Legitimate peripheral participation. Cambridge, UK: Cambridge University Press.

Wenger, E. (2002) Cultivating communities of practice: A guide to managing knowledge. Boston: Harvard Business School Publishing.

You, Y. (1993) What we can learn from chaos theory? An alternative approach to instructional systems design. Educational Technology Research Development. 41(3), 17-32.

Zhao, Y., Lei, J., Yan, B., Lai, C., Tan, H. S. (2005). What makes the difference? A practical analysis of research on the effectiveness of distance education" Teachers College Record. 107(8), 1836-1884.

S. Ntim is a Professor of Psychology of Education. He holds PhD in Psychology of Education from the Salesian Pontifical University of Rome. Currently, he is the Dean of Internationalization and Institutional Advancement of the Catholic University of Ghana and a staff of the Education Faculty.

$\mathrm{He}$ is a prolific writer and has published profusely especially in the areas of Education and Psychology.

Prof. is a member of the International Association of Cognitive Psychology and a member of the Ghana Psychology Council. He has varied research interests from Philosophy to Religion, but particularly in the area of the interface between human cognition and learning and its implications for classroom teaching.

M. Opoku-Manu holds Master of Philosophy in Educational Psychology from the University of Cape Coast in Ghana, a Bachelor's degree in the study of Religions from the University of Ghana, 2007 and a Diploma in Basic Education from the University of Cape Coast (2008).

His research interests are in the areas of learning and motivation. He is a Lecturer at the Faculty of Education of the Catholic University of Ghana.

A. Kwarteng Addai-Amoah, is a Senior Research Assistant in the Faculty of Education of the Catholic University of Ghana.

He holds the Bachelor Education in English from the University of Cape Coast and is currently pursuing Master of Philosophy in English at the University of Ghana.

His research interests are in Educational Technology and English. 